\title{
POLÍTICA DE SAÚDE NO CÁRCERE FLUMINENSE: IMPACTOS DA PANDEMIA DE COVID-19
}

\section{POLITICAL HEALTH INSIDE RIO DE JANEIRO'S PRISON SYSTEM: IMPACTS OF COVID-19 PANDEMIC}

\author{
NATÁlia LUCERO FRIAS TAVARES ${ }^{1}$ \\ RODRIGO GRAZINOLI GARRIDO \\ ANTONIO EDUARDO RAMIRES SANTORO 3
}

\begin{abstract}
RESUMO: O presente trabalho tem por propósito analisar as políticas públicas de saúde para as pessoas presas no Estado do Rio de Janeiro e seus impactos para o enfrentamento da pandemia do 2019-nCoV. O problema que se presente enfrentar é: quais as medidas para mitigar os efeitos da pandemia de coronavírus foram tomadas em relação ao direito à saúde das pessoas presas no Estado do Rio de Janeiro? E secundariamente: no que a falta de uma política pública de saúde no cárcere pode impactar a sociedade no âmbito da pandemia de COVID-19? Para tanto desenvolveu-se uma pesquisa quali-quantitativa, a partir de fontes documentais, sobre as cifras prisionais, sobre o impacto da COVID-19 no mundo e suas possibilidades de enfrentamento, bem como uma análise das medidas que vem sendo adotadas no Brasil e, especialmente, no Estado do Rio de Janeiro.
\end{abstract}

Palavras-Chave: Encarceramento; Direitos da Pessoa Presa; Coronavírus; COVID-19; Pandemia.

\footnotetext{
${ }^{1}$ Professora visitante do programa de pós graduação da ABDCONST/RJ. Doutoranda em Direito pela UFRJ. Mestra em Direito pela Universidade Católica de Petrópolis (UCP). Especialização em Direito Penal, Processo Penal e Criminologia pela UCAM/RJ. Graduada em Direito pela UERJ. Advogada criminalista. Endereço eletrônico <natalialuceroadv@gmail.com>.

2 Professor Adjunto da FND/UFRJ; Professor Adjunto do PPGD/UCP; Pós Doutorado pela UFRJ; Doutor em Ciências pela UFRRJ; Mestre em Ciências Farmacêuticas pela UFRJ; Graduado em Biomedicina pela Unirio; Licenciado em Biologia; Graduado em Segurança Pública pela UFF; Perito Criminal do Instituto de Pesquisa e Perícias em Genética Forense/SEPOL/RJ. Endereço eletrônico < grazinoli.garrido@gmail.com>.

3 Professor Titular do IBMEC/RJ; Professor Adjunto do PPGD/UFRJ; Professor Adjunto do PPGD/UCP; Pós Doutorado pela Universidade de Coimbra; Doutor e Mestre pela UFRJ; Mestre pela Universidade de Granada; Advogado criminalista. Endereço eletrônico <antoniosantoro@direito.ufrj.br>.
} 
ABSTRACT: The purpose of this paper is to analyze public health policies for people imprisoned in the State of Rio de Janeiro and their impact on coping with the coronavirus pandemic. The problem to be faced is: what measures have been taken to mitigate the effects of the $2019-\mathrm{nCoV}$ pandemic in relation to the right to health of prisoners in the state of Rio de Janeiro? And secondly: how can the lack of a public health policy in prison impact society in the context of the COVID-19 pandemic? To this end, a quali-quantitative research was developed, based on documentary sources, on prison figures, on the impact of COVID-19 in the world and its possibilities of coping, as well as an analysis of the measures that have been adopted in Brazil and, especially, in the state of Rio de Janeiro.

KeYWORDS: Imprisionment; Inmates' Rights; Coronavirus; COVID-19; Pandemic.

\section{INTRODUÇÃo}

O artigo 196 da Constituição Federal de 1988 dispõe que "a saúde é direito de todos e dever do Estado, garantido mediante políticas sociais e econômicas que visem à redução de doença e de outros agravos e ao acesso universal e igualitário às ações e serviços para sua promoção, proteção e recuperação".

Sendo a saúde um direito fundamental inerente a toda e qualquer pessoa, conforme prevê o próprio texto constitucional em diferentes dispositivos, bem como a legislação extravagante, reputa-se inquestionável sua relevância tanto para fins de alocação de investimento quanto priorização no que tange à implementação de políticas públicas.

A despeito da existência e vigência do texto legal, em muitos momentos é possível questionar se sua aplicabilidade de fato abrange a integralidade dos indivíduos da população. Tal questionamento surge no momento em que notícias relativas pandemia de coronavírus, a COVID-19, uma vez que é altamente contagioso e basta a proximidade entre as pessoas para que o risco se agrave.

Partindo da premissa de que a pena de prisão deve apenas privar o apenado do desfrute irrestrito da liberdade ambulatorial, sem acarretar limitação ou exclusão de sua dignidade humana e tutela dos direitos e garantias fundamentais por parte do Estado, coloca-se aqui um questionamento: Quais as medidas para mitigar os efeitos da pandemia de coronavírus foram tomadas em relação ao direito à saúde das pessoas presas no Estado do Rio de Janeiro? No que a falta de uma política pública de saúde no cárcere pode impactar a sociedade no âmbito da pandemia de COVID-19?

Tendo por base fundante a certeza de que a assistência no cuidado e prevenção de doenças é assegurada aos indivíduos que compõem a sociedade brasileira independentemente de suas características pessoais, o presente trabalho 
tem por objeto central de análise a gestão da saúde no ambiente prisional. Considerando que o indivíduo privado de liberdade passa todo seu tempo sob a tutela direta do Estado, configura um contrassenso o abandono patente da saúde prisional.

Utilizando os princípios limitadores e balizadores da pena, pretende-se, ao longo do texto, trabalhar por intermédio da análise qualitativa as cifras prisionais, a maneira como o direito à saúde das pessoas que se encontram em situação de privação de liberdade é ou não afetado em virtude da atribuição do rótulo de "criminoso". Ainda pretende-se realizar uma abordagem sobre o novo coronavírus (2019-nCoV) e, mais especificamente a COVID-19, suas características, atualidades e perspectivas, para então analisar seu potencial impacto no âmbito do sistema prisional. Por fim, far-se-á uma análise das medidas que vêm sendo tomadas para evitar ou minorar o risco do contágio entre a população encarcerada no Estado do Rio de Janeiro.

\section{O ENCARCERAMENTO E A NATURALIZAÇÃO DA DESUMANIZAÇÃO DA PESSOA PRESA}

De acordo com as últimas estatísticas oficiais divulgadas pelo Departamento Penitenciário Nacional (2017), mais de 726 mil pessoas encontravam-se privadas de liberdade (Figura 1). Tal quantitativo alçou o país à terceira posição no ranking mundial de maiores populações prisionais. Levantamento mais recente do Banco de Monitoramento de Prisões do Conselho Nacional de Justiça aponta para um contingente prisional de 812.564 .

Figura 1: Evolução das Pessoas Privadas de Liberdade entre 1990 e 2016

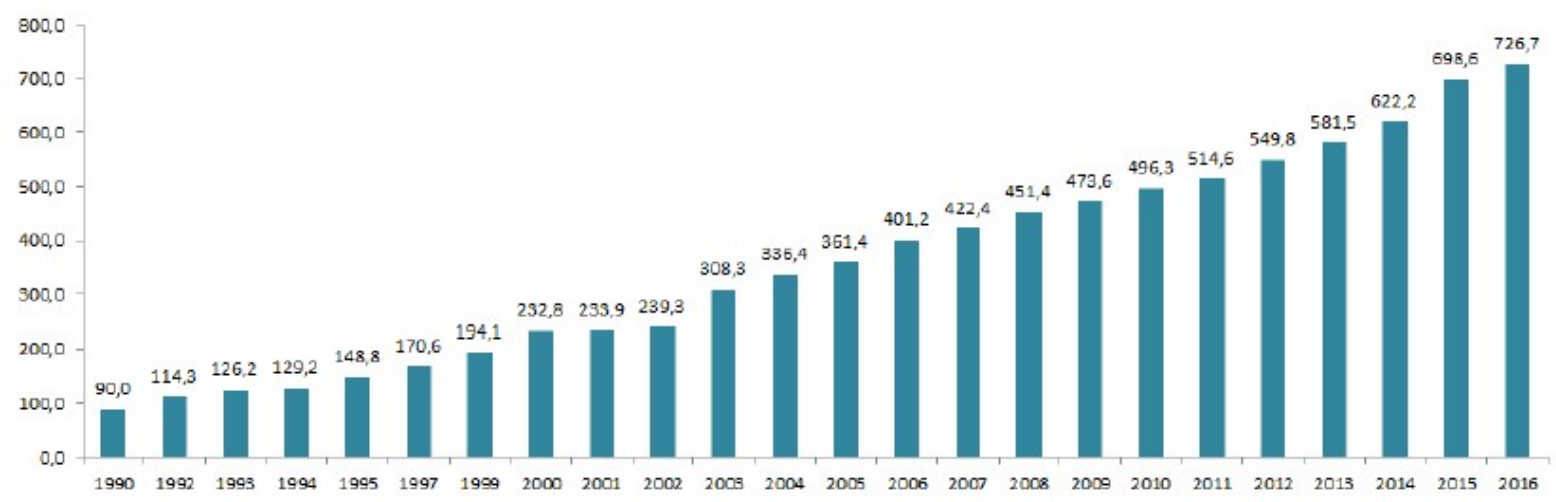

Fonte: Levantamento nacional de informações penitenciárias: INFOPEN atualização - junho de 2016 divulgado pelo Departamento Penitenciário Nacional em dezembro de 2017.

Ainda que isoladamente já seja possível constatar a magnitude desta cifra, a mesma se torna ainda mais alarmante quando se considera que: (1) nem todas as unidades prisionais do país forneceram dados de efetivo carcerário para 
contabilização; (2) sob a perspectiva dinâmica, considerando que $40 \%$ deste efetivo é composto de presos cautelares, o número de indivíduos que passarão ao longo de um ano pelos muros dos estabelecimentos penais será muito mais elevado.

Segundo o último Infopen, apenas $21 \%$ dos estabelecimentos prisionais brasileiros possuem um contingente prisional dentro da capacidade prevista. Dentre os demais, 41\% apresentam índices de ocupação entre 101\% e 200\%; outros $20 \%$ apresentam taxas de ocupação que representam entre $201 \%$ e $300 \%$ de sua capacidade total; $5 \%$ das instituições prisionais acomodam efetivo que equivale entre $301 \%$ e $400 \%$ de sua capacidade; enquanto 11\% (leia-se, 155 unidades prisionais) apresentam índice de ocupação superior a $401 \%$ de sua capacidade total (INFOPEN, 2017, p. 27).

Ou seja, com uma taxa de ocupação média de 197,4\% (Infopen, 2017. p.7), as penitenciárias brasileiras encontram-se superlotadas ${ }^{4}$, não dispondo de estrutura para abrigar dignamente aquelas pessoas que se encontram sob a tutela penal do Estado.

Entretanto, as mazelas vivenciadas pelas pessoas presas não provocam grande comoção social. Por um conjunto de motivos que não se pretende esgotar aqui, opera-se um processo de invisibilização dos apenados e apenadas que em muito se aproxima do conceito de vida nua delineado por Giorgio Agamben (2014).

Ao tratar dos objetivos do Direito Penal em suas obras, Juarez Cirino dos Santos faz uma clara distinção entre os denominados “objetivos declarados" e os velados (seus efetivos desdobramentos), apontando a grande interseção existente entre este ramo do direito e a desigualdade social. Afirma o autor (SANTOS, 2014. p.10):

O significado político do controle social realizado pelo Direito Penal e pelo Sistema de Justiça Criminal aparece nas funções reais desse setor do Direito - encobertas pelas funções declaradas do discurso oficial: a criminalização primária realizada pelo Direito Penal (definição legal

\footnotetext{
${ }^{4} \mathrm{O}$ fenômeno da superlotação carcerária não é novidade no cenário brasileiro: desde a implementação do modelo de política de guerra às drogas na década de '90 (MALAGUTI, 2011, p. 97ss) o número de prisões segue em exponencial ascensão. Uma breve análise do perfil das pessoas privadas de liberdade no Brasil ilustra com clareza as repercussões desta estratégia estatal: $26 \%$ dos homens se encontram hoje nos estabelecimentos em decorrência da prática de crimes ligados ao tráfico de drogas; dentre as mulheres, o percentual de encarceramentos decorrentes de práticas ligadas ao comércio de entorpecentes equivale a $62 \%$ do efetivo (INFOPEN, 2017, p. 43). Com a manutenção do modelo proibicionista centrado na privação de liberdade, as expectativas quanto às cifras do cárcere são pessimistas: a tendência observada é de que os números de prisões sigam uma crescente, intensificando os problemas já comuns nas unidades (insalubridade, superlotação, etc).
} 
de crimes e de penas) e a criminalização secundária realizada pelo Sistema de Justiça Criminal constituído pela polícia, justiça e prisão (aplicação e execução de penas criminais) garantem a existência e a reprodução da realidade social desigual das sociedades contemporâneas.

Cirino dos Santos chama atenção para a maneira como o Direito Penal - por meio da criminalização de determinadas condutas - atende aos interesses das classes sociais hegemônicas, assegurando a manutenção de seu status quo.

O processo de criminalização primária traduz claramente as escolhas de política criminal de seu local de inserção em virtude da natureza dos bens jurídicos tutelados: inexistindo em nosso ordenamento qualquer direito absoluto ${ }^{5}$ ou ordem de importância e prevalência pré-estabelecidas, o ato de conferir proteção penal a determinado bem jurídico não é automático ou óbvio, mas uma construção. Ou seja, no momento que o legislador elabora uma norma prevendo que a lesão a determinado bem jurídico é tão grave a ponto de justificar o exercício do poder punitivo estatal, atua de forma política, criando a diferenciação entre comportamentos desejáveis e indesejáveis (e consequentemente, puníveis).

\section{SAÚdE NO AMBIENTE PRISIONAL BRASILEIRA E FLUMINENSE: UM PROBLEMA DE SAÚDE DOS PRESOS E DA SOCIEDADE}

O advento da Constituição Federal de 1988 simbolizou real marco de redemocratização após um período de mais de duas décadas de regime ditatorial militar. No título destinado à ordem social, o constituinte originário inseriu expressamente a proteção do direito à saúde.

A redação do artigo 196 da CRFB/88 estabelece que "a saúde é direito de todos e dever do Estado, garantido mediante políticas sociais e econômicas que visem à redução do risco de doença e de outros agravos e ao acesso universal e igualitário às ações e serviços para sua promoção, proteção e recuperação".

A a promoção da saúde não está direcionada apenas à prevenção da doença. A promoção da saúde envolve fatores como a busca pela qualidade de vida, garantindo que a população viva em ambiente saudável e protegida contra riscos de adoecimento (WINTER; GARRIDO, 2017, p.6).

Nos estabelecimentos prisionais, as condições precárias de salubridade, superlotação e carência de recursos contribuem para o processo de disseminação

\footnotetext{
${ }^{5}$ Nenhum direito - ainda que garantido por cláusula pétrea - é absoluto. Deste modo, sempre que diferentes direitos ou garantias colidem não existe uma ordem pré-determinada de prevalência ou sacrifício, demandando a realização de um estudo do caso concreto para determinar qual deverá prosperar naquela hipótese específica. Nem mesmo o direito à vida é absoluto, sendo admitida pena de morte nas hipóteses do inciso XLVII, alínea "a" do art. 5 da CRFB/88.
} 
de uma pluralidade de doenças que aparecem em incidência superior à observada fora dos limites prisionais.

Para melhor compreender a maneira como a proliferação de doenças em estabelecimentos prisionais repercute sobre pessoas que não se encontram em regime de privação de liberdade, dividiu-se a análise em dois movimentos: os riscos à saúde pública decorrentes da rotatividade da população carcerária e aqueles criados pelo movimento de entrada e permanência de pessoas não presas em ambiente prisional, que violam o que é conhecido como princípio da intranscendência.

Ao apresentar em sua obra "Direito penal brasileiro: primeiro volume - Teoria Geral do Direito Penal" o conceito de princípio da intranscendência da pena, Zaffaroni et l. (2015, p. 32) fazem expressa menção a alguns dos tipos de transbordamentos que decorrem do mero exercício do poder punitivo:

o Estado de polícia estende a responsabilidade a todos que cercam o infrator, pelo menos por não terem denunciado sua atividade, e considera sua família perigosa, porque seus membros podem vingálo. Tais características se acentuam nos delitos que afetam a existência do estado, que no estado de polícia se confunde com o governo. Por isso, por meio do terror incentiva a delação e consagra a corrupção de sangue. No estado de direito a responsabilidade penal deve ser individual e não pode transcender a pessoa do delinqüente. Daí o fato de nossa Constituição prever que "nenhuma pena passará da pessoa do condenado" (art.5o, inc. XLV CR). Entretanto, essa transcendência do poder punitivo na direção de terceiros é, de fato, inevitável: a comunicação, o conhecimento, a estigmatização, a queda dos rendimentos etc., são todos efeitos que inevitavelmente alcançam a família do simples acusado e mesmo outras pessoas. Nossa legislação contém poucos dispositivos no sentido de atenuá-los, como, por exemplo, o auxílio-reclusão, de natureza previdenciária (art. 80, lei no. 8213 , de 24 . jul.91). Um efeito transcendente de prisonização sem embargo da tímida previsão legal da visita íntima (art. 40, inc. X, LEP), na prática subordinada à maior ou menor liberalidade da administração - é a privação de relações sexuais, que deixa ao cônjuge ou companheiro não-institucionalizado a opção entre abstinência ou dissolução do vínculo afetivo.

Também chamado de princípio da personalidade ou intranscendência da pena, o princípio da pessoalidade encontra-se consagrado no ordenamento no artigo 5º, inciso XLV da CRFB/88, gozando de status de cláusula pétrea. Dispõe a 
redação do referido dispositivo que "nenhuma pena passará da pessoa do condenado, podendo a obrigação de reparar o dano e a decretação do perdimento de bens ser, nos termos da lei, estendidas aos sucessores e contra eles executadas, até o limite do valor do patrimônio transferido".

Inserido no ordenamento brasileiro desde a Constituição de $1824^{6}$, é o princípio da pessoalidade da pena que assegura a todos a certeza de que a punição proveniente do cometimento de um ilícito repousará apenas sobre os ombros de quem concorreu para a prática da violação.

A análise do princípio da intranscendência da pena proposta no presente estudo não pretende se deter apenas ao aspecto objetivo atingido por tal previsão, qual seja: a imposição de pena apenas contra quem seja considerado responsável por determinada prática delituosa. Na realidade, o foco central de análise não é a decisão condenatória, mas sim a observância do princípio da pessoalidade durante o curso do cumprimento de pena.

O que será tratado aqui são os efeitos que a inobservância do direito à saúde das pessoas encarceradas geram não apenas para elas, mas também para sobre a sociedade. Trata-se de um efeito deletério da violação por transcendência do direito à saúde no cárcere.

Segundo levantamento realizado em parceria pelo Ministério Público do Rio e Janeiro e o Instituto Igarapé (2016) com base nos dados fornecidos pela Secretaria de Administração Penitenciária (SEAP), apenas no estado do Rio de Janeiro houve uma média de cinco mortes de presos por mês entre os anos de 2010 e 2016. Dentre os 442 óbitos computados no período, listam-se 278 mortes decorrentes de doença e 17 falecimentos resultantes de insuficiência respiratória.

Os desdobramentos letais decorrentes de doenças não se limitam ao sistema prisional fluminense, contudo, a falta de transparência dos dados fornecidos pelos levantamentos oficiais (que não assinalam de forma clara os casos de falecimento por doença) impossibilita a realização de um cálculo de proporções. (Tabela 1).

\footnotetext{
${ }^{6}$ Durante a vigência das Ordenações Filipinas, admitia-se que a punição ultrapassasse a figura do autor do delito, podendo a punição se estender a seus familiares. Um exemplo famoso na história brasileira é o da condenação imposta a Joaquim José da Silva Xavier, popularmente conhecido como Tiradentes. A sentença condenatória determinava: "Portanto condenam ao réu Joaquim José da Silva Xavier, por alcunha o Tiradentes, alferes que foi da tropa paga da Capitania de Minas, a que, com baraço e pregão, seja conduzido pelas ruas públicas ao lugar da forca, e nela morra morte natural para sempre, e que depois de morto lhe seja cortada a cabeça e levada a Vila Rica, onde no lugar mais público será pregada em um poste alto, até que o tempo a consuma, e o seu corpo será dividido em quatro quartos, e pregados em postes, pelo caminho de Minas, no sítio da Varginha e das Cebolas, onde o réu teve a suas infames práticas e os mais nos sítios de maiores povoação, até que o tempo também os conota, declaro o réu infame, e seus filhos e netos tendo-os, e os seus bens aplicam para o Fisco e Câmara Real, e a casa em que vivia em Vila Rica será arrasada e salgada, para que nunca mais no chão se edifique, e não sendo própria será avaliada e paga ao seu dono pelos bens confiscados, e no mesmo chão se levantará um padrão pelo qual se conserve em memória a infâmia deste abominável réu".
} 
Sendo a população prisional brasileira formada por 726.712 pessoas segundo consta no próprio levantamento, ao multiplicar-se os números apresentados na tabela anterior de modo a refletir a quantidade total de mortes no sistema prisional, os resultados obtidos são os seguintes: ocorreram ao menos 988 mortes em ambiente prisional apenas no primeiros semestre de 2016, sendo 559 foram listadas como "naturais" (categoria que também engloba mortes por doenças).

Tabela 1. Taxa de mortalidade para cada 10 mil pessoas privadas de liberdade no primeiro semestre de 2016 por natureza de morte e unidade

\begin{tabular}{|c|c|c|c|c|c|c|}
\hline UF & $\begin{array}{c}\text { Óbitos } \\
\text { naturais }\end{array}$ & $\begin{array}{l}\text { Óbitos } \\
\text { criminais }\end{array}$ & $\begin{array}{c}\text { Óbitos } \\
\text { suicídios }\end{array}$ & $\begin{array}{c}\text { Óbitos } \\
\text { acidentais }\end{array}$ & $\begin{array}{l}\text { Óbitos com causa } \\
\text { desconhecida }\end{array}$ & $\begin{array}{c}\text { Total de } \\
\text { óbitos }\end{array}$ \\
\hline AC & 0,0 & 5,6 & 0,0 & 0,0 & 0,0 & 5,6 \\
\hline AL & 3,1 & 4,6 & 0,0 & 0,0 & 0,0 & 7,6 \\
\hline AM & 4,9 & 6,8 & 0,0 & 0,0 & 0,0 & 11,7 \\
\hline AP & 0,0 & 7,5 & 0,0 & 0,0 & 11,2 & 18,7 \\
\hline BA & 7,2 & 2,4 & 3,2 & 0,8 & 4,0 & 17,5 \\
\hline CE & 2,2 & 11,5 & 0,0 & 0,0 & 26,4 & 40,1 \\
\hline DF & 4,0 & 2,7 & 2,0 & 0,0 & 2,0 & 10,6 \\
\hline ES & 5,7 & 0,5 & 0,0 & 0,0 & 0,0 & 6,2 \\
\hline GO & 3,7 & 6,8 & 2,5 & 0,0 & 0,6 & 13,5 \\
\hline MA & 16,9 & 5,2 & 2,6 & 0,0 & 0,0 & 24,7 \\
\hline MG & 5,2 & 4,5 & 1,2 & 0,3 & 0,5 & 11,7 \\
\hline MS & 12,7 & 2,8 & 2,2 & 2,2 & 0,0 & 19,9 \\
\hline MT & 7,7 & 1,0 & 0,0 & 0,0 & 0,0 & 8,7 \\
\hline PA & 6,5 & 10,9 & 0,7 & 1,4 & 4,3 & 23,9 \\
\hline PB & 3,5 & 9,7 & 1,8 & 1,8 & 0,9 & 17,6 \\
\hline PE & 11,3 & 6,7 & 0,6 & 0,6 & 0,6 & 19,7 \\
\hline PI & 17,4 & 17,4 & 0,0 & 2,5 & 0,0 & 37,2 \\
\hline PR & 6,0 & 1,0 & 0,2 & 0,0 & 0,2 & 7,4 \\
\hline RJ & NI & NI & NI & NI & $\mathrm{NI}$ & NI \\
\hline RN & 4,6 & 12,6 & 1,1 & 0,0 & 6,9 & 25,3 \\
\hline RO & 7,4 & 2,8 & 0,9 & 0,0 & 0,0 & 11,1 \\
\hline RR & 0,0 & 0,0 & 0,0 & 0,0 & 0,0 & 0,0 \\
\hline RS & 11,2 & 1,8 & 0,0 & 0,6 & 0,6 & 14,2 \\
\hline SC & 11,2 & 0,5 & 0,0 & 0,5 & 0,0 & 12,1 \\
\hline SE & 10,0 & 2,0 & 0,0 & 10,0 & 2,0 & 23,9 \\
\hline SP & 8,7 & 0,4 & 0,7 & 0,0 & 0,4 & 10,3 \\
\hline TO & 8,7 & 11,5 & 5,8 & 0,0 & 0,0 & 26,0 \\
\hline Brasil & 7,7 & 3,0 & 0,8 & 0,4 & 1,6 & 13,6 \\
\hline
\end{tabular}

Fonte: Levantamento Infopen - Junho/2016 (2017).

Nota: As amostras analisadas referem-se apenas ao primeiro semestre do ano de 2016 (01/01/2016 a 30/06/2016). Os óbitos resultantes de doença foram computados na categoria "óbitos naturais". 
Segundo o Ministério da Saúde, as doenças que aparecem em maior índice nos estabelecimentos prisionais são a tuberculose (WINTER; GARRIDO, 2017. p7), as doenças sexualmente transmissíveis, dermatoses e hepatites. Os índices de manifestação desta doença nos estabelecimentos prisionais superam consideravelmente àqueles da sociedade em geral.

Para melhorar ilustrar a forma de ocorrência da hipótese de transcendência que aqui pretende-se delinear, é necessário deixar de lado momentaneamente a questão da saúde nas penitenciárias brasileiras, para tecer comentários sobre a perspectiva dinâmica da população privada de liberdade (SANTORO;TAVARES; GOMES, 2017).

Ao comparar os dados fornecidos pelos levantamentos publicados retroativamente pelo Departamento Penitenciário Nacional, alguns pontos relevantes podem ser apontados: de dezembro de 2015 até junho de 2016, a população carcerária brasileira passou de 698.618 (Infopen referente à dezembro/2015, 2017. p.7) para 726.721(INFOPEN, 2017, p. 7); no ano de 2015 o sistema teve um total de 469.013 entradas originárias e 353.637 saídas definitivas de interno (não entrando neste computo as transferências e saídas temporárias); só no primeiro semestre de 2016, o número de ingressos foi 266.133 contra 193.789 saídas.

Mesmo não contendo dados a respeito de todas as movimentações ocorridas no sistema prisional, a mera constatação do fluxo de entradas e saídas acima listados permite concluir que o número de pessoas que sofreram privação de liberdade no Brasil ao longo de determinado período não se resume à cifra do número de internos, sendo necessário acrescentar ao cálculo todos aqueles que por ali passaram.

Levando em conta apenas os números oficiais do Depen, o número de pessoas que estiveram no cárcere brasileiro apenas no primeiro semestre de 2016 equivale ao somatório de permanências e saídas, chegando a um total de 920.501. Já o somatório dos números apurados durante o ano inteiro de 2015 chega a um total de 1.052.255 pessoas ${ }^{7}$.

Uma das práticas que contribui ativamente para o agravamento desse risco é o uso da prisão provisória pelo Poder Judiciário brasileiro. Considerando que $40 \%$ (Infopen, 2017. p.13) desses indivíduos estão presos provisórios, inexiste contra eles qualquer certeza de condenação, sendo sua manutenção em ambiente prisional contrária ao modelo traçado pelo constituinte originário que tem em suas bases a presunção de inocência e a liberdade como regra.

A inserção em ambiente prisional de pessoas que não necessariamente serão condenadas ao cumprimento de uma pena privativa de liberdade, causa os

\footnotetext{
${ }^{7}$ Não havendo dados que permitam verificar com exatidão o número de egressos que saíram do cárcere mas foram presos novamente no curso do mesmo ano, é possível que esses números sejam incompatíveis com a realidade fática.
} 
seguintes desdobramentos: (i) coloca em ambiente insalubre e inseguro indivíduos que, segundo as normas legais vigentes, deve ser considerado presumidamente inocente; (ii) agrava o problema da superlotação carcerária; (iii) provoca um aumento da rotatividade da população carcerária; (iv) aumenta os riscos de disseminação de doenças também no exterior dos presídios, funcionando os egressos como uma espécie de vetores.

Também durante a realização de atividades laborativas extramuros, saídas temporárias e deslocamento do interno para comparecimento a fóruns, delegacias e afins se opera esta interação entre internos e sociedade externa.

Feitos esses esclarecimentos introdutórios sobre a relação entre população dinâmica, fluxo de saída de pessoas das penitenciárias e risco de proliferação de doenças, colocam-se alguns esclarecimentos. Primeiramente, não se está defendendo em hipótese alguma a permanência da privação de liberdade como medida assecuratória do direito à saúde da coletividade, mas defendendo a necessidade de oferecer condições de higiene e saúde adequadas no âmbito dos estabelecimentos prisionais para que as doenças que ali se proliferam sejam tratadas e prevenidas.

Quanto à rotatividade populacional nos confins prisionais, o que se propõe como alternativa imediata e viável é reduzir de forma drástica a permanência de presos provisórios nestes locais. Para isso, medidas como a realização de audiências de custódia, isenção do pagamento de fiança e colocação de indivíduos em prisão albergue domiciliar são só algumas das alternativas já existentes e implementadas (timidamente) no Brasil.

De forma geral, aduz-se que a estrutura prisional hoje existente atenta contra o princípio da pessoalidade da pena por ferir o direito à saúde de pessoas estranhas ao direito penal em decorrência das deploráveis condições de lotação, higiene e salubridade em que são acondicionadas as pessoas presas.

Não obstante os riscos de aumento da disseminação de doenças que podem ocorrer em virtude da rotatividade da população prisional, a proteção da saúde de pessoas não privadas de liberdade também pode ser atingida em razão da forma de estruturação do próprio modelo prisional.

Para que uma penitenciária funcione, é necessário que se tenha não apenas uma estrutura física adequada, mas também mão de obra para realizar as diferentes atividades que ali se tem de desenvolver, como: cuidar da segurança, oferecer tratamento médico, gerir a parte administrativa, etc. Ou seja, permanecem no interior dos estabelecimentos prisionais tanto as pessoas privadas de pena quanto aquelas que ali trabalham.

De acordo com o último levantamento, entre funcionários efetivos $(75 \%)$, comissionados $(2 \%)$, terceirizados $(5 \%)$ e temporários $(18 \%)$, havia um total de 105.215 pessoas trabalhando na ativa em 30/06/2016 (INFOPEN, 2017, p. 46-47). 
As doenças contagiosas não diferenciam indivíduos com base nas informações constantes de sua folha de antecedentes criminais, sendo os funcionários expostos a quase tanto risco ${ }^{8}$ de contágio de doença quanto os internos.

Além dos agentes penitenciários, outras pessoas ingressam diariamente em penitenciárias pelo país, parte delas a trabalho (como é o caso de advogados, juízes, assistentes sociais, pastores, voluntários, etc), enquanto outras o fazem para visitar seus companheiros, parentes e amigos privados de liberdade.

Segundo o Levantamento do MP e Instituto Igarapé citado anteriormente, ainda que no Rio de Janeiro haja presídios em dez municípios, os estabelecimentos recebem visitantes de todas as 92 cidades do estado. De acordo com os pesquisadores do Igarapé, para as quase 51 mil privadas de liberdade no Rio de Janeiro em 2016, havia 80 mil visitantes cadastrados.

O descaso com as condições de manutenção do sistema prisional atinge diretamente todas as pessoas que por lá passam, oferecendo riscos à saúde (e à vida) dos mesmos, configurando mais um tipo de transcendência dos efeitos da condenação. Assim como mencionado no item anterior, a melhoria nas condições prisionais proporciona benefícios não apenas à pessoa presa, mas à sociedade de modo integral.

Portanto, a simples adoção do modelo de política de segurança público fundado mormente na aplicação de pena privativa de liberdade acaba por produzir efeitos que reverberam para fora dos muros prisionais e podem ter um impacto importante na não contenção dos efeitos da pandemia de COVID-19.

Faz-se necessário, dessa forma, entender melhor a pandemia do COVID-19.

\section{IV.COVID-19 (SARS-COV-2): A PANDEMIA QUE VEM ABALANDO O MUNDO}

O agente etiológico da COVID-19 ou SARS-CoV-2 é um novo coronavirus (2019-nCoV). Esses vírus são conhecidos desde a década de 1960, mas foi em 2003 que os coronavírus foram responsáveis primeiramente por um significativo número de casos da síndrome respiratória aguda grave (SARS-CoV), considerada, na época, uma doença emergente (WU, 2020).

Em meados de novembro de 2019, um número importante de pessoas da Província de Hubei, na China, buscou os serviços de saúde com quadros graves de insuficiência respiratória. A questão foi levantada pelo Dr. Li Wenliang no Hospital Central de Wuhan, o qual faleceu em 6 de fevereiro de 2020, acometido pela nova doença. De fato, tratava-se de um quadro agudo de insuficiência

\footnotetext{
8 Não se pode afirmar que o nível de exposição dessas pessoas se iguala em virtude da permanência dos funcionários no local se operar apenas durante seus turnos de trabalho. Ademais, a ocorrência de contato físico dos agentes com presos doentes se dá de maneira mais branda, uma vez que não permanecem no interior de celas superlotadas e não partilham do uso das dependências reservadas aos internos.
} 
respiratória, com demanda de ventilação mecânica, de pessoal especializado e de ações emergenciais de saúde pública para o isolamento de assintomáticos e bloqueio da região. Ainda assim, muitas pessoas realizaram, até início de fevereiro de 2020, viagens em função das comemorações em torno do Ano Novo Chinês, o que deflagrou inúmeros focos de COVID-19.

Ainda em 3 de janeiro de 2020, foi identificado o genoma completo do 2019nCoV a partir da amostra de fluido bronquioalveolar de um paciente de Wuhan (TAN et al., 2020). No final deste nês, o Comitê de Vigilância Internacional para as Doenças Transmissíveis da OMS reconheceu os critérios para decretar uma Emergência de Saúde de Âmbito Internacional (WHO, 2020a).

A COVID-19 apresenta uma ampla sintomatologia, variando de infecção leve a infecção respiratória aguda grave. Entre os sinais e sintomas detectados, Denis, Vandeweerd e Van der Vliet (2020), conseguiram reunir de diversos relatos os seguintes: febre, tosse, falta de ar (dispneia), dor muscular (mialgia), fadiga, confusão mental, dor de cabeça, dor de garganta, rinorreia, dor no peito, diarréia, náusea e vômito, síndrome do desconforto respiratório agudo. Os três primeiros são os mais comumente relatados e os demais encontram-se em ordem de frequência. No entanto, pacientes hospitalizados podem apresentar diferentes graus de cada um deles (DENIS; VANDEWEERD; VAN DER VLIET, 2020).

O diagnóstico tem sido feito através da observação dos sintomas, que, no entanto, são comuns a outras síndromes respiratórias (CHEN et al., 2020). A piora no prognóstico pode ser monitorada com o auxílio, p.ex., de imagens pulmonares (GUAN et al., 2020). Além disso, laboratorialmente, pode ser observada redução na contagem de linfócitos (CHEN et al., 2020) e eosinófilos (LI et al., 2020); elevação da proteína C reativa (ZHANG et al., 2020); e alterações nos parâmetros de coagulação e bioquímicos, como da albumina, lactato desidrogenase e angiotensina II, que mostra elevação associada à carga viral e à lesão pulmonar (LIU et al., 2020). Contudo, a certeza da infecção pelo 2019-nCoV é oferecida, logo no início, pelo teste molecular pelo RT-PCR (Reação em Cadeia da PolimeraseTranscriptase Reversa) e, mais tardiamente, pelos testes rápidos imunológicos (IgM / IgG).

A taxa de mortalidade parece crescer rapidamente em pacientes com idade superior a 50 anos $(1,3 \%)$, alcançando $14,8 \%$ em pacientes maiores de 80 anos, independentemente de comorbidades (NOVEL CORONAVIRUS PNEUMONIA EMERGENCY RESPONSE EPIDEMIOLOGY TEAM, 2020). Contudo, na maioria dos casos de óbito, observava-se comorbidades $(76,8 \%)$, incluindo hipertensão $(56,1 \%)$, doença cardíaca $(20,7 \%)$, diabetes $(18,3 \%)$, doença cerebrovascular $(12,2 \%)$ e câncer $(7,3 \%)$ (FENG; LI; ZHANG, 2020). A associação com doença cardíaca pode ter ainda maior importância, pois verificou-se em pacientes hospitalizados de Wuhan lesões no coração provocadas pelo vírus (SHI; QIN; SHEN, 2020). 
Como em outros vírus respiratórios, as observações sugerem transmissão através de objetos contaminados, aerossolização de vírus em um espaço confinado ou pela proximidade a pessoas infectadas com sintomas ou não (CAI et al., 2020). Deve-se atentar que, mesmo após recuperados, pacientes ainda podem ter vírus mantendo a transmissão (LAN et al., 2020).

Inicialmente, preconizou-se que o vírus, semelhante ao que ocorreu na SARSCov-1, seria disperso apenas através de gotículas grandes que logo se depositariam nas superfícies (WILDER-SMITH; FREEDMAN, 2020), mas foi determinado que o agente pode permanecer viável e infeccioso em aerossóis por até três horas e em superfícies, como plástico, vidro, aço inoxidável, cobre e papelão, por até três dias (DOREMALEN et al., 2020). Apesar do novo coronavirus persistir em superfície, é inativado pela limpeza com álcool (62-71\%), peróxido de hidrogênio $(0,5 \%)$ ou hipoclorito de sódio $(0,1 \%)$ (KAMPF et al., 2020). Para a antissepsia da superfície corpórea, especialmente mãos e antebraços, água e sabão parece ser suficiente (ANVISA, 2009).

Já foram encontrados (SUN et al., 2020) vírus em descargas oculares em um paciente com conjuntivite, embora o sintoma seja raro na COVID-19, assim, os autores sugeriram uma via potencial de infecção nosocomial. Zhang, Du, Li et al (2020) também relataram a detecção de vírus em suabes anais, principalmente em estágios mais tardios da doença. Xiang, Yan, Liu e colaboradores (2020) encontraram vírus nas fezes de metade dos pacientes com resultado positivo. A transmissão fecal pode ser apoiada pela diarreia encontrada em pacientes antes do desenvolvimento de febre e dispneia (WANG et al., 2020). A transmissão vertical (mãe-filho) não parece acontecer (CHEN; GUO; WANG, 2020). Provavelmente aconteceria transmissão através de produtos sanguíneos não testados (CHANG; YAN; WANG, 2020).

Quanto ao tratamento, muita pesquisa vem sendo realizada em busca de um medicamento contra o vírus (LU, 2020). Vários fármacos anti retrovirais, como os originalmente utilizados contra HIV/AIDS e outras patologias, já foram propostos. São exemplos desses medicamentos com aplicação divergente daquela especificada em bula, "off-label", os inibidores da entrada de vírus na célula hospedeira, aí se encontra a cloroquina, p.ex.; inibidores da RNA polimerase, que participa da replicação do material genético do vírus; inibidores de protease, que impedem a construção do complexo de replicação viral, entre outros sítios são alvos de ação desses fármacos. Os sintomas iniciais podem ser manejados com o uso de antiinflamatórios não esteroidais. Contudo há discussão quanto à utilização especificamente do Ibuprofeno e possível piora do caso (DENIS; VALERIE; VAN DER VLIET, 2020).

Da mesma forma, a busca por imunoprevenção tem estimulado muitas pesquisas e acompanhado pela OMS (WHO, 2020b). Apesar da alguma homologia de sequência entre SARS-CoV-2 e SARS-CoV e, em menor grau, MERSCoV, não se espera que candidatos a vacina desenvolvidos contra estes 
gerem níveis adequados de reação para o novo coronavírus, demandando vacinas com antígenos específicos de SARS-CoV-2. Há relato de que de dois meses após o surto de SAR-CoV-2, pelo menos 37 empresas biofarmacêuticas ou setores acadêmicos estavam na corrida para desenvolver uma vacina por meio de mRNA, DNA, vetor adenoviral e proteína recombinante (PROMPETCHARA; KETLOY; PALAGA, 2020). Por outro lado, a ideia de um soro contendo imunoglobulina obtida de convalescentes tem ganhado força como prevenção e tratamento da doença, de certo modo, remontando terapêuticas do séc. XIX (CASADEVALL; PIROFSKI, 2020).

Assim, na ausência de vacinas para a prevenção ou de uma terapêutica farmacológica adequada à cura, o enfrentamento ao surto de Coronavírus, causador da COVID-19 (SARS-CoV-2), tem requerido medidas clássicas de saúde pública. Entre essas práticas, encontramos a quarentena, o isolamento e a contenção social, as quais têm como função impedir a propagação da doença entre pessoas, interrompendo a transmissão do vírus (WILDER-SMITH; FREEDMAN, 2020).

As medidas de quarentena, isolamento e contenção social são fundamentais para o enfrentamento da pandemia. De acordo com a Revista Nature, antes das ações restritivas de contato, calculava-se que cada infectado infectaria outras oito pessoas, de forma que $40 \%$ da população chinesa (500 milhões de pessoas) seria infectadas. Após sete dias da implantação das medidas na China, o número de infectados, a partir de um transmissor, caiu para 1,05 (CYRANOSKI, 2020), servindo de exemplo para outros países que passam pela pandemia.

\section{Medidas de Contenção dos efeitos da PANDEMIA de COVID- 19}

O Governador do Estado do Rio de Janeiro, seguindo a recomendação da OMS para realizar a quarentena, o isolamento e a contenção social, tomou várias medidas, em Decretos sucessivos, para evitar os efeitos da pandemia de COVID19.

No dia 13 de março de 2020, o Governador publicou o Decreto no 46.970, no dia 16 de março de 2020, publicou o Decreto no 46.973, no dia 19 de março de 2020, publicou o Decreto $\mathrm{n}^{\mathrm{o}} 46.980$ e, no dia 30 de março de 2020, publicou o Decreto $\mathrm{n}^{\mathrm{o}}$. 47.006. Há várias diferenças entre eles, todas restringindo por 15 dias a circulação de pessoas e o funcionamento de estabelecimentos, mas em todos há 3 (três) disposições da mesma natureza sobre os direitos das pessoas presas:

Em primeiro lugar, fica suspensa a visitação às unidades prisionais, inclusive aquelas de natureza íntima. Em segundo lugar, fica suspenso o transporte de detentos para realização de audiência, cabendo ao Secretário de Estado de Administração Penitenciária apresentar a justificativa ao órgão jurisdicional 
competente. Em terceiro e último lugar, a visita de advogados a presídios do Estado deve ser ajustada pelo Secretário do Estado de Administração Penitenciária para possibilitar o atendimento das medidas do Decreto. A despeito do texto ser igual em todos os Decretos, parece que nos dois últimos Decretos, ao inserir essa previsão na listagem de atividades suspensas, houve uma inversão quanto à compreensão, ou seja, está suspenso, a menos que o Secretário possibilite.

De toda forma, parece claro que a opção do Governador em relação às pessoas presas não tem nenhuma relação com a preservação da saúde dos detentos, porquanto promove um isolamento dos mesmo em relação ao resto da sociedade, ao passo que os detentos continuam amontoados em constante contato físico, incrementando o risco de contágio do vírus, contrariamente às medidas mundiais de enfrentamento da pandemia.

O Judiciário, de outro lado, também discutiu especificamente as medidas as serem tomadas para evitar a disseminação do vírus da COVID-19 entre os detentos do país inteiro. O IDDD - Instituto de Defesa do Direito de Defesa Marcio Thomaz Bastos, admitido como terceiro interessado na Ação de Descumprimento de Preceito Fundamental (ADPF) no 347 proposta pelo PSOL Partido Socialismo e Liberdade, pleiteou pela petição no 14.137/2020 tutela provisória incidental para que os juízos competentes analisem a possibilidade de deferimento de: (1) liberdade condicional a encarcerados com idade igual ou superior a sessenta anos, nos termos do artigo 1o da Lei no 10.741, de 1o de outubro de 2003; (2) regime domiciliar aos soropositivos para HIV, diabéticos, portadores de tuberculose, câncer, doenças respiratórias, cardíacas, imunodepressoras ou outras suscetíveis de agravamento a partir do contágio pelo novo coronavírus; (3) regime domiciliar às gestantes e lactantes, na forma da Lei no 13.257, de 8 de março de 2016 - Estatuto da Primeira Infância; (4) regime domiciliar a presos por crimes cometidos sem violência ou grave ameaça; (5) substituição da prisão provisória por medida alternativa em razão de delitos praticados sem violência ou grave ameaça; (6) medidas alternativas a presos em flagrante ante o cometimento de crimes sem violência ou grave ameaça; (7) progressão de pena a quem, atendido o critério temporal, aguarda exame criminológico; e (8) progressão antecipada de pena a submetidos ao regime semiaberto.

O Relator, Ministro Marco Aurélio de Mello, em decisão proferida no dia 17 de março de 2020 às $22 \mathrm{~h} 30$, negou seguimento ao pedido de tutela provisória incidental por entender que o terceiro interessado não tem legitimidade para formular tal pedido.

Todavia, o Ministro entendeu que, diante da situação "dos presídios e penitenciárias, no que levou o Colegiado Maior, na medida cautelar na arguição de descumprimento de preceito fundamental no $347 / \mathrm{DF}$, a concluir pelo estado de coisas inconstitucional, considerada a integridade física e moral dos custodiados", o Plenário do Supremo Tribunal Federal deveria pronunciar-se sobre o tema e, de 
ofício, conclamou os juízos da execução dos Tribunais de Justiça e dos Tribunais Regionais Federais a analisarem com urgência as medidas na forma pleiteadas pelo IDDD, em razão da pandemia de COVID-19.

O Plenário do Supremo Tribunal Federal, por sua vez, inobstante tenha por unanimidade acompanhado o Ministro Relator quanto ao entendimento sobre a ilegitimidade do terceiro interessado, negou por ampla maioria (apenas o Ministro Gilmar Mendes o acompanhava) a determinação de ofício para os Juízos da Execução.

Prevaleceu o entendimento, capitaneado pela divergência inaugurada pelo Ministro Alexandre de Moraes no sentido de prestigiar a Recomendação no 62 do CNJ - Conselho Nacional de Justiça, expedida em 17 de março de 2020, que expediu diversas recomendações, inclusive aos magistrados com competência na fase de conhecimento na apuração de atos infracionais e de execução das medidas socioeducativas, de forma geral para evitar as medidas de internação.

Porém deve se destacar que foram feitas recomendações aos magistrados com competência para a fase de conhecimento criminal e de execução penal. Aos magistrados com competência na fase de conhecimento criminal, recomendou-se: (1) a reavaliação das prisões provisórias, nos termos do art. 316 do CPP, priorizando-se (a) mulheres gestantes, lactantes, mães ou pessoas responsáveis por criança de até doze anos ou por pessoa com deficiência, assim como idosos, indígenas, pessoas com deficiência ou que se enquadrem no grupo de risco; (b) pessoas presas em estabelecimentos penais que estejam com ocupação superior à capacidade, que não disponham de equipe de saúde lotada no estabelecimento, que estejam sob ordem de interdição, com medidas cautelares determinadas por órgão do sistema de jurisdição internacional, ou que disponham de instalações que favoreçam a propagação do novo coronavírus; (c) prisões preventivas que tenham excedido o prazo de 90 (noventa) dias ou que estejam relacionadas a crimes praticados sem violência ou grave ameaça à pessoa; (2) a máxima excepcionalidade de novas ordens de prisão preventiva, observando-se o protocolo das autoridades sanitárias.

Aos magistrados com competência sobre a execução penal, recomendou-se: (1) a concessão de saída antecipada dos regimes fechado e semiaberto, nos termos das diretrizes fixadas pela Súmula Vinculante no 56 do Supremo Tribunal Federal, sobretudo em relação às: (a) mulheres gestantes, lactantes, mães ou pessoas responsáveis por criança de até 12 anos ou por pessoa com deficiência, assim como idosos, indígenas, pessoas com deficiência e demais pessoas presas que se enquadrem no grupo de risco; (b) pessoas presas em estabelecimentos penais com ocupação superior à capacidade, que não disponham de equipe de saúde lotada no estabelecimento, sob ordem de interdição, com medidas cautelares determinadas por órgão de sistema de jurisdição internacional, ou que disponham de instalações que favoreçam a propagação do novo coronavírus; (2) 
alinhamento do cronograma de saídas temporárias ao plano de contingência previsto no artigo 9o da presente Recomendação, avaliando eventual necessidade de prorrogação do prazo de retorno ou adiamento do benefício, assegurado, no último caso, o reagendamento da saída temporária após o término do período de restrição sanitária; (3) concessão de prisão domiciliar em relação a todos as pessoas presas em cumprimento de pena em regime aberto e semiaberto, mediante condições a serem definidas pelo Juiz da execução; (4) colocação em prisão domiciliar de pessoa presa com diagnóstico suspeito ou confirmado de COVID-19, mediante relatório da equipe de saúde, na ausência de espaço de isolamento adequado no estabelecimento penal; (5) suspensão temporária do dever de apresentação regular em juízo das pessoas em cumprimento de pena no regime aberto, prisão domiciliar, penas restritivas de direitos, suspensão da execução da pena (sursis) e livramento condicional, pelo prazo de noventa dias.

$\mathrm{O}$ que se verifica não é uma convergência completa entre as medidas propostas pelo IDDD e deferidas pelo Ministro Marco Aurélio e as Recomendações, mas há sensíveis pontos de toque. Enquanto o IDDD pediu que as gestantes e lactantes ficassem em regime domiciliar na forma da Lei $\mathrm{n}^{\mathrm{o}}$ 13.257/2016, que trata apenas de prisão domiciliar para os casos de preventiva, a Recomendação do CNJ é ao mesmo tempo mais genérica (porque não especifica que deva ser concedida a prisão domiciliar, apenas determina a revisão) e mais ampla (porque abrange também a execução penal).

$O$ pedido do IDDD fala em liberdade condicional para idosos e regime domiciliar para os portadores de determinadas doenças, ao passo que a Recomendação trata genericamente do grupo de risco e não fala em prisão domiciliar, mas em reavaliação da prisão provisória e saída antecipada dos regimes fechado e semiaberto. Ao passo que o IDDD pede regime domiciliar para presos por crimes sem violência ou grave ameaça, a Recomendação do CNJ fala em regime domiciliar para pessoa presa com diagnóstico suspeito ou confirmado de COVID-19.

O IDDD pede a substituição de prisão provisória por medida alternativa, se o delito for sem violência ou grave ameaça, a Recomendacão fala em reavaliação de prisões preventivas que ultrapassem 90 dias ou se o crime não for com violência ou grave ameaça. A Recomendação ainda trata de usar um critério de máxima excepcionalidade para novas ordens de prisão preventiva. Prevê a reavaliação das prisões provisórias e a concessão de saída antecipada dos regimes fechado e semiaberto para as pessoas presas em estabelecimentos penais que estejam com ocupação superior à capacidade, que não disponham de equipe de saúde lotada no estabelecimento, que estejam sob ordem de interdição, com medidas cautelares determinadas por órgão do sistema de jurisdição internacional, ou que disponham de instalações que favoreçam a propagação do novo coronavírus.

Se for cumprida essa determinação à risca, parece que não poderia ser mantida qualquer pessoa presa no Estado do Rio de Janeiro, o que não tem como se 
acreditar que ocorrerá. Fato é que, em decorrência da Recomendação 62/2020 do CNJ e da decisão do STF no pedido de Tutela Provisória Incidental na ADPF no 347, foi enviado o Ofício no 11/2020 no dia 20 de março de 2020 Secretário de Estado de Administração Penitenciária do Rio de Janeiro, ao Presidente do Tribunal de Justiça do Estado do Rio de Janeiro e ao Procurador-Geral de Justiça do Estado do Rio de Janeiro, subscrito pelo IDDD, pelo DDH - Instituto de Defensores de Direitos Humanos, pelo Instituto IDEAS, pelo CESeC - Centro de Estudos de Segurança e Cidadania, pelo Conectas Direitos Humanos, pelo ITTC Instituto Terra, Trabalho e Cidadania, pela Justiça Global, pelo Instituto Sou da Paz, pelo Centro de Ciências Jurídicas e Econômicas da UFRJ, pelo NIDH Núcleo de Direitos Humanos da FND-UFRJ e pela Clínica de Direitos Humanos UERJ-UFRJ, requerendo fossem tomadas as medidas necessárias para que se dê imediato cumprimento às recomendações do $\mathrm{CNJ}$.

Ainda no dia 20 de março de 2020, a Defensoria Pública do Estado do Rio de Janeiro impetrou um habeas corpus coletivo (processo $\mathrm{n}^{\mathrm{o}}$ 0061178994.2020.8.19.0001) visando autorizar a saída de presos com 60 anos ou mais do Presídio Evaristo de Moraes, como forma de dar cumprimento à Recomendação 62/2020 do CNJ. O desembargador plantonista deferiu liminar para que os juízes competentes analisassem no prazo de dez dias todos os pedidos de benefícios. No dia 23 de março de 2020, todavia, o Presidente do Tribunal de Justiça, atendendo a um pedido do Ministério Público do Estado, suspendeu a liminar concedida.

A Defensoria Pública do Estado do Rio de Janeiro impetrou o Habeas Corpus no 568.752 perante o Superior Tribunal de Justiça, e em decisão de 26 de março de 2020 concedendo a liminar requerida, o Ministro Nefi Cordeiro entendeu haver "flagrante incompetência e ilegalidade no uso da suspensão de segurança para cassação de liminar em habeas corpus e anulou a decisão da Presidência do Tribunal de Justiça, restabelecendo o prazo de dez dias para que os juízes reavaliassem a prisão das pessoas idosas na forma da Recomendação 62/2020 do CNJ.

Em decisão do dia 25 de março de 2020, o Superior Tribunal de Justiça, por decisão do Ministro Paulo de Tarso Sanseverino, atendendo ao pedido da Defensoria Pública da União, estendeu a todos os presos por prisão alimentícia do país a liminar concedida aos casos do Estado do Ceará para que a prisão seja convertida em prisão domiciliar.

Nesse mesmo dia, a pedido da Defensoria Pública do Estado do Rio de Janeiro, a Justiça suspendeu por 20 dias o cumprimento de medidas socioeducativas de liberdade assistida para adolescentes em razão do coronavírus porque exigiria o comparecimento junto com o responsável em Centros de Referência de Assistência Social, violando a ordem de isolamento social. 
No dia 28 de março de 2020, o PSOL, junto com as Defensorias Públicas do Estado do Rio de Janeiro e de São Paulo, o IBCCRIM - Instituto Brasileiro de Ciências Criminais e o Instituto Conectas Direitos Humanos, peticionaram na ADPF 347 fazendo uma série de requerimentos. Desta feita, não se poderá negar seguimento ao pedido por tratar-se de requerimento formulado por amici curiae porque PSOL foi o partido político autor da ADPF.

Nessa petição o PSOL pede providências não apenas judiciais para diminuir os impactos da pandemia de coronavírus nas prisões brasileiras, mas também para que o Poder Executivo tome medidas para os internos, tais como se abster de praticar o racionamento de água, provejam assistência material com entrega de produtos de higiene e limpeza das celas, forneça equipamentos de proteção aos agentes públicos de administração penitenciária e socioeducativa, bem como mantenham equipes mínimas de saúde nas unidades prisionais.

Requer, ainda, como forma de controlar o cumprimento da decisão, que todas as ações tomadas para cumprí-la sejam imediatamente comunicadas ao Departamento de Monitoramento e Fiscalização do Sistema Carcerário e Sistema de Execução de Medidas Socioeducativas - DMF, do Conselho Nacional de Justiça, bem como ao Comitê para o acompanhamento e supervisão das medidas de prevenção ao contágio pelo Novo Coronavírus - COVID-19 pelos tribunais brasileiros, também instituído no âmbito do CNJ.

Parece claro que ignorar o cumprimento de medidas urgentes de saúde pública em relação às pessoas encarceradas, não é apenas lhes negar um direito fundamental à saúde, mas incrementar o risco de propagação do vírus para a sociedade como um todo, tendo em vista a transcendência dos efeitos não diretos da pena, conforme já abordado neste trabalho.

Todavia, na prática não apenas as medidas de prevenção à propagação do vírus no âmbito prisional não mereceram do Governo do Estado do Rio de Janeiro a mesma atenção dispensada à população em geral, como até o conhecimento sobre o impacto da pandemia nas prisões do Rio de Janeiro restará desconhecido do público.

Em Resolução Conjunta SEPOL/SEAP no 10 de 23 de março de 2020, a Secretaria do Estado de Polícia Civil e a Secretaria do Estado de Administração Penitenciária, determinaram que a necropsia dos óbitos ocorridos no sistema prisional não se realizará. De acordo com a Resolução, somente os casos de morte por causa externa ou suspeita serão submetidos à perícia pelo Instituto Médico Legal, os demais óbitos serão declarados pelos médicos da SEAP.

Com isso, não se terá conhecimento da extensão dos efeitos da pandemia de coronavírus no sistema prisional fluminense, bem como da sua propagação para o meio exterior. O mínimo que se poderia esperar sobre as periciais, seria que o exame de integridade do preso que é encaminhado ao sistema prisional, incluísse também a testagem sobre o coronavírus, sob pena de se admitir que seja colocado 
junto com pessoas que não estão infectadas, outras que se encontram ou não se sabe se estão infectadas.

\section{VI.CONSIDERAÇÕES FINAIS}

Embora a privação de liberdade ocupe posição inequívoca de destaque e aceitação majoritária por parte da sociedade brasileira, a mesma apenas pode ser aplicada em conformidade com os limites estabelecidos de maneira clara pela legislação vigente.

Ainda que a alusão a argumentos contrários ao expansionismo penal e naturalização (inadequada) do uso da pena de prisão pareça indispensável neste momento histórico atual, objetivando manter estrita referência ao recorte ora proposto, apresenta-se aqui uma clara crítica à maneira como a prevalência das noções arcaicas de aproximação de pena à ideia de penitência e sofrimento ainda se sustenta. Tal visão, além de equivocada é incompatível com um modelo de sociedade democrática, acaba por autorizar tacitamente a inércia estatal ante a proteção e efetivação dos direitos das pessoas privadas de liberdade.

A despeito das noções de neutralização decorrentes do conceito de prevenção geral negativa, a prisão não é (ou, ao menos, não deveria ser) sinônimo de risco à vida ou à saúde da pessoa presa.

Desta feita, considerando o estado de grave vulnerabilidade em que se encontra a pessoa privada de liberdade e a responsabilidade que recai sobre os ombros de Estado de zelar por estas pessoas de quem retira a liberdade ambulatorial (e tantos outros direitos), é inadmissível o abandono e parca assistência dispensados a esta questão. O respeito e atenção à saúde da população prisional merece posição de destaque não apenas pelos possíveis impactos que doenças do cárcere podem gerar na saúde da sociedade em geral (tratando-se de hipótese de transcendência da pena), mas sim por tratar-se, antes de mais nada, de condição para a manutenção de uma existência minimamente digna daqueles indivíduos aprisionados.

Mas afinal, voltando aos problemas que motivaram o presente trabalho: quais as medidas para mitigar os efeitos da pandemia de coronavírus foram tomadas em relação ao direito à saúde das pessoas presas no Estado do Rio de Janeiro? No que a falta de uma política pública de saúde no cárcere pode impactar a sociedade no âmbito da pandemia de COVID-19?

Parece claro que as únicas medidas tomadas em relação às pessoas presas para mitigar os efeitos da pandemia foram de tentativa de isolamento do cárcere com a sociedade. Ao contrário das diversas tentativas realizadas por órgãos de defesa dos direitos humanos e defensorias públicas, com algumas decisões do Poder Judiciário e do $\mathrm{CNJ}$, o Poder Executivo não se preocupou com a saúde das pessoas encarceradas. 
Mais ainda, pelo que se viu, sequer será possível mensurar exatamente os efeitos práticos dessa pandemia no âmbito das prisões do Estado do Rio de Janeiro. A invisibilidade da pessoa presa e os objetivos não declarados do sistema prisional estão no centro das políticas públicas sobre saúde no cárcere.

\section{REFERÊNCIAS}

BARBOSA, Filipe. Após morte e casos de meningite em presídios no RJ, servidores denunciam negligência na imunização. G1 Disponível em: <https:/g1.globo.com/rj/norte-fluminense/noticia/2019/06/12/apos-morte-e-casosde-meningite-em-presidio-no-rj-servidores-denunciam-negligencia-naimunizacao.ghtml>. Acesso em 20 mar. 2020

BRASIL. Agência Nacional de Vigilância Sanitária. Segurança do Paciente em Serviços de Saúde - Higienização das Mãos. Brasília, 2009.

BRASIL. Departamento Penitenciário Nacional. Levantamento Nacional de Informações Penitenciárias: INFOPEN Mulheres Junho de 2014. Disponível em: $<$ http://bit.ly/in- fopenmulheres>. Acesso em 6 out 2017.

CAI, J. et al. Indirect Virus Transmission in Cluster of COVID-19 Cases. Emerg Infect Dis, v. 26, n. 6, 2020. DOI: https://doi.org/10.3201/eid2606.200412.

CASADEVALL, A.; PIROFSKI, L. The convalescent sera option for containing COVID-19. J. Clin Invest, 2020. DOI: https://doi.org/10.1172/JCI138003.

CHANG L; YAN Y; WANG L. Coronavirus Disease 2019: Coronaviruses and Blood Safety. Transfus Med Rev, 2020. DOI: https://doi.org/10.1016/j.tmrv.2020.02.003

CHEN, H. et al. Clinical characteristics and intrauterine vertical transmission potential of COVID-19 infection in nine pregnant women: a retrospective review of medical records. The Lancet, v. 395, 2020, p. 809-815. DOI: https://doi.org/10.1016/S0140-6736(20)30360-3.

CHEN, G. et al. Clinical and immunologic features in severe and moderate forms $\begin{array}{llll}\text { of Coronavirus } & \text { Disease. }\end{array}$ DOI: https://doi.org/10.1101/2020.02.16.20023903. 
CIRINO DOS SANTOS, Juarez. Direito Penal - Parte Geral. 6. ed. Curitiba: ICPC Cursos e Edições, 2014.

CYRANOSKI, DAVID. What China's coronavirus response can teach the rest of the world. Nature, 2020. DOI: https://10.1038/d41586-020-00741-x.

DENIS, M.; VANDEWEERD, V.; VAN DER VLIET, D. Overview of information available to support the development of medical countermeasures and interventions against COVID-19. Transdisciplinary Insights - Living Paper, 2020.

DOREMALEN, N. Van et al. Aerosol and Surface Stability of SARS-CoV-2 as Compared with SARS-CoV-1. N. Engl. J. Med, 2020. DOI: 10.1056/NEJMc2004973.

FENG, Z. et al. The Novel Coronavirus Pneumonia Emergency Response Epidemiology Team. China CDC Weekly, v. 2, n. 8, p. 113-122, 2020. DOI: 10.3760/cma.j.issn.0254-6450.2020.02.003.

GARRIDO, Rodrigo Grazinoli; RODRIGUES, Eduardo Leal. O Banco de Perfis Genéticos Brasileiro Três Anos após a Lei no 12.654. Revista de Bioetica y Derecho, v. 35, p. 94-107, 2015.

GUAN, W.J. et al. China Medical Treatment Expert Group for COVID-19. Clinical Characteristics of Coronavirus Disease 2019 in China. N Engl J Med, 2020. DOI: 10.1056/NEJMoa2002032.

KAMPF, G. et al. Persistence of coronaviruses on inanimate surfaces and its inactivation with biocidal agents. J Hosp Infect, v. 104, n. 3, 2020, p. 246-251. DOI: https://doi.org/10.1016/j.jhin.2020.01.022.

LAN, L. et al. Positive RT-PCR Test Results in Patients Recovered From COVID19. JAMA, 2020. DOI:10.1001/jama.2020.2783.

LI, Q. et al. A simple laboratory parameter facilitates early identification of $\begin{array}{lll}\text { COVID-19 patients. } & \text { MedRxiv, }\end{array}$ DOI: https://doi.org/10.1101/2020.02.13.20022830. 
LIU, Y. et al. Clinical and biochemical indexes from 2019-nCoV infected patients linked to viral loads and lung injury. Sci China Life Sci, v. 63, n, 3, 2020, p. 364374. DOI: https://doi.org/10.1007/s11427-020-1643-8.

LU, H. Drug treatment options for the 2019-new coronavirus (2019-nCoV). Biosci Trends. 2020. DOI: https://10.5582/bst.2020.01020.

Novel Coronavirus Pneumonia Emergency Response Epidemiology Team. The epidemiological characteristics of an outbreak of 2019 novel coronavirus diseases (COVID-19) in China. Zhonghua Liu Xing Bing Xue Za Zhi, v. 41, n. 2, 2020, p.145-151. Disponível em: <http://weekly.chinacdc.cn/en/article/id/e53946e2-c6c441e9-9a9b-fea8db1a8f51>. Acesso em 25 mar 2020.

PROMPETCHARA, E.; KETLOY, C.; PALAGA, T. Immune responses in COVID19 and potential vaccines: Lessons learned from SARS and MERS epidemic. Asian Pac J Allergy Immunol, v. 38, 2020, p. 01-09. DOI: 10.12932/AP-200220-0772.

SHI, S. et al. Association of Cardiac Injury With Mortality in Hospitalized Patients With COVID-19 in Wuhan, China. JAMA Cardiol, 2020. DOI:10.1001/jamacardio.2020.0950.

SUN, W. et al. The infection evidence of SARS-COV-2 in ocular surface: a singlecenter cross-sectional study. 2020. DOI: https://doi.org/10.1101/2020.02.26.20027938.

TAN, W. et al. A Novel Coronavirus Genome Identified in a Cluster of Pneumonia Cases - Wuhan, China 2019-2020. China CDC Weekly, v. 2, n. 4, 2020, p. 61-62. DOI: 10.1056/NEJMoa2001017.

WANG, D. et al. Clinical Characteristics of 138 Hospitalized Patients With 2019 Novel Coronavirus-Infected Pneumonia in Wuhan, China. JAMA, v. 323, n. 11, 2020, p. 1061-1069. DOI: https://doi.org/10.1001/jama.2020.1585.

WHO. Statement on the second meeting of the International Health Regulations (2005) Emergency Committee regarding the outbreak of novel coronavirus (2019nCoV). 2020a. Disponível em: <https://www.who.int/news-room/detail/30-012020-statement-on-the-second-meeting-of-the-international-health-regulations(2005)-emergency-committee-regarding-the-outbreak-of-novel-coronavirus-(2019ncov)>. Acesso em: 25 mar. 2020. 
WHO. DRAFT landscape of COVID-19 candidate vaccines - 20 March. 2020b. Disponível em: <https://www.who.int/blueprint/priority-diseases/keyaction/novel-coronavirus-landscape-ncov.pdf?ua=1>. Acesso em 25 mar 2020.

WILDER-SMITH, A.; FREEDMAN, D. O. Isolation, quarantine, social distancing and community containment: pivotal role for old-style public health measures in the novel coronavirus (2019-nCoV) Outbreak. Journal of Travel Medicine, 2020, p. 1-4, 2020. DOI: 10.1093/jtm/taaa020.

WINTER, Bárbara Carollo de Almeida; GARRIDO, Rodrigo Grazinoli. A tuberculose no cárcere: um retrato das mazelas do sistema prisional brasileiro. Medicina Legal de Costa Rica, v. 34, 2017, p. 01-12.

WU, P. et al. Real-time tentative assessment of the epidemiological characteristics of novel coronavirus infections in Wuhan, China, as at 22 January 2020. Euro Surveill, v. 25, n. 3, 2020. DOI: 10.2807/1560-7917.ES.2020.25.3.2000044\#r11.

XIANG, J. et al. Evaluation of Enzyme-Linked Immunoassay and Colloidal GoldImmunochromatographic Assay Kit for Detection of Novel Coronavirus (SARSCov-2) Causing an Outbreak of Pneumonia (COVID-19). MedRxiv, 2020. DOI: https://doi.org/10.1101/2020.02.27.20028787.

ZAFFARONI, Eugenio R; BATISTA, Nilo; ALAGIA, Alejandro; SLOKAR, Alejandro. Direito Penal Brasileiro: primeiro volume - Teoria Geral do Direito Penal. 4 ed. Rio de Janeiro: Revan, 2011.

ZHANG, B. et al. Clinical characteristics of 82 death cases with COVID-19. MedRxiv, 2020. DOI: https://doi.org/10.1101/2020.02.26.20028191

ZHANG, W. et al. Molecular and serological investigation of 2019-nCoV infected patients: implication of multiple shedding routes. Emerg Microbes Infect, v. 9, n. 1, p.386-389, 2020. DOI: https://doi.org/10.1080/22221751.2020.1729071.

ZHANG, J. et al. Therapeutic and triage strategies for 2019 novel coronavirus disease in fever clinics. Lancet Respir Med, 2020. DOI: https://doi.org/10.1016/S2213-2600(20)30071-0. 